\title{
Obstructive Sleep Apnea Related Symptom Prevalence in Patients with Headache Presented to Neurology Outpatient Clinic: Results of a Preliminary Study*
}

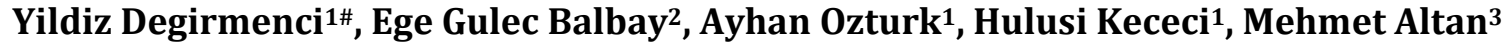 \\ ${ }^{1}$ Neurology Department, School of Medicine, Duzce University, Duzce, Turkey \\ ${ }^{2}$ Pulmonology Department, School of Medicine, Duzce University, Duzce, Turkey \\ ${ }^{3}$ Neurology Department, Mus State Hospital, Mus, Turkey \\ Email: "ydegir@gmail.com, egegulecbalbay@gmail.com, ayvann@yahoo.com, hulusikececi@hotmail.com, \\ drmehmetaltan@gmail.com
}

Received 13 June 2014; revised 12 July 2014; accepted 11 August 2014

Copyright (C) 2014 by authors and Scientific Research Publishing Inc.

This work is licensed under the Creative Commons Attribution International License (CC BY).

http://creativecommons.org/licenses/by/4.0/

(c) (i) Open Access

\begin{abstract}
Approximately $20 \%$ of patients with sleep apnea will have headaches and $25 \%$ of patients with other sleep disorders will also experience headaches. We aim to evaluate sleep apnea related symptom prevalence in patient with headache presenting to neurology outpatient clinics. Twenty four patients with headache were asked for sleep apnea symptoms. The prevalence of snoring, excessive daytime sleepiness and witnessed apnea was $33.3 \%, 20.8 \%$ and $4.2 \%$, respectively. Among sleep apnea symptoms, the presence of at least one symptom, at least two symptoms and all three symptoms were $9(37.5 \%), 4(16.7 \%)$ and $1(4.2 \%)$, respectively. The frequency of major symptoms of sleep apnea syndrome was high in patient with nonspecific headache. In the light of literature review, in case of a suspicion of sleep disorder in a headache patient, it would be appropriate to question the major symptoms of OSAS, and to refer the patient to a polysomnographic evaluation for an objective diagnosis. This approach would be helpful to improve the quality of life of patients with headache.
\end{abstract}

\section{Keywords}

Headache, Obstructive Sleep Apne Syndrome, Neurology Practice

${ }^{*}$ This study has been presented as poster presentation in the 48th Turkish National Neurology Congress, 16-22 November 2012, Antalya, Turkey.

${ }^{\#}$ Corresponding author.

How to cite this paper: Degirmenci, Y., Gulec Balbay, E., Ozturk, A., Kececi, H. and Altan, M. (2014) Obstructive Sleep Apnea Related Symptom Prevalence in Patients with Headache Presented to Neurology Outpatient Clinic: Results of a Preliminary Study. Neuroscience \& Medicine, 5, 177-182. http://dx.doi.org/10.4236/nm.2014.54020 


\section{Introduction}

Obstructive sleep apnea syndrom (OSAS) is a common sleep disorder of general population, with an estimated prevalence of $2 \%$ and $7 \%$ in adult population [1]. It can be defined as repeated episodes of obstructive apneas and hypopneas during sleep, frequently followed by transient hypoxemia, hypercapnia, sleep fragmentation, unconscious arousals, and daytime sleepiness, which can lead to various somatic and mental problems. Thus, the severity of the symptom includes the combination of the severity of daytime sleepiness, and the value of apnea-hypopnea index (AHI) [1] [2].

While OSAS causes sleep fragmentation due to snoring and body movements between the apneic events, as well as the apnea periods, it can severely impair the quality of life of patients suffering from the disease [3]. Common daytime effects of OSAS include excessive daytime sleepiness, irritability, decreased cognition, personality and mood changes such as depression or anxiety, and headaches [4].

Headache is one of the neurological manifestations of OSAS and irrespective of diagnosis; chronic daily, morning, or "awakening" headache patterns are soft signs of a sleep disorder. Sleep apnea headache may emerge de novo or may present as an exacerbation of cluster, migraine, tension-type, or other headache [5]. The possible mechanisms underlying the pathogenesis of headache in OSAS are night-time fluctuations of oxygen saturation during the night with hypercapnia, vasodilatation, increased intracranial pressure and impaired sleep quality. However, the exact mechanisms of headache pathogenesis in the disease remain controversial [6] [7].

In the light of literature knowledge revealing the relationship between OSAS and headache, we aim to determine the obstructive sleep apnea symptom prevalence in patients with headache presenting to neurology outpatient clinic.

\section{Materials and Methods}

Patients with a new and/or prior diagnosis of headache who admitted to the neurology outpatient clinic of Duzce Medical Faculty Hospital were enrolled the study. All participants were informed about the content of the study and gave their written approval. Socio-demographic characteristics were obtained in a structured interview using an open questionnaire completed in person with all participants.

Headache assessment was made with a face-to-face interview in our neurology outpatient clinic. The patients who presented with a headache complaint were asked about the characteristic features of their headaches in order to make accurate diagnosis and the diagnosis of headache was made on the basis of the criteria of the International Classification of Headache Disorders, $2^{\text {nd }}$ edition (Headache Classification Subcommittee of the International Headache Society-IHS) [8].

Sleep disturbance in general and excessive daytime sleepiness were evaluated in all participants. The assessment of sleep disturbance was made with a questionnaire including major OSAS symptoms such as snoring (presence of snoring for at least 5 nights per week), witnessed apnea (spouse or relatives of patients with OSAS, identifying noisy and irregular snoring, and stopped respiration through the mouth and nose) and day time sleepiness, as well as minor symptoms (choking sensation during sleep, atypical chest pain, sleep split, insomnia, decreased ability to decide, concentration problems, palpitation, weight gain, personality changes, mood changes, abnormal motor activity during sleep, dry mouth, morning headaches, nocturnal cough and enuresis).

Epworth sleepiness scale (ESS) was used to evaluate excessive daytime sleepiness (Table 1). The questionnaire asks the subject to rate his or her probability of falling asleep on a scale of increasing probability from 0 to 3 for eight different situations that most people engage in during their daily lives, though not necessarily every day. The scores for the eight questions are added together to obtain a single number. A total score above 10 subjectively indicates excessive daytime sleepiness, which is accepted as a clinical feature of OSAS [9].

Data were organized in a SPSS version 19.0 (Statistical Package for Social Sciences for Windows) database. Statistical analyses were performed using the same program. Mean and standard deviation of data were calculated and descriptive analyses were performed. P values $<0.05$ were considered to indicate statistical significance.

\section{Results}

Twenty-four patients with headache complaint were enrolled the study. There were 11 men (45.8\%), and 13 women (54.2\%). Mean age of the patients were $42.79 \pm 20.04$ years (range $=17-89$ years). 
When the headache types of patients were evaluated according to the IHS criteria, fifteen patients had unclassified headaches with nonspecific features [8]. The remaining 9 patients were diagnosed as migraine $(n=4$, $16.6 \%)$, tension-type headache ( $\mathrm{n}=3,12.5 \%)$, acute sinusitis $(\mathrm{n}=1,4.2 \%)$, and morning headache $(\mathrm{n}=1$, 4.2\%).

The answers of the questionnaire assessing the frequency of OSAS symptoms in patients with headache were shown in Table 2. Nine (37.5\%) patients were experiencing major symptoms of OSAS, while fifteen (62.5\%) had no complaints. Among the major symptoms, the prevalence of snoring was 33.3\%, excessive daytime sleepiness was $20.8 \%$, and witnessed apnea was $4.2 \%$. When we assessed the co-existence of the major symptoms, we found that $37.5 \%(n=9)$ of the patients were experiencing at least one major symptom of OSAS, while $16.7 \%$ $(\mathrm{n}=4)$ had two symptoms, and $4.2 \%(\mathrm{n}=1)$ of the patients were suffering from three major symptoms OSAS (Table 2).

When we further analyzed the frequency of major OSAS symptoms according to the diagnosis of headaches in patients, we found that the major symptoms of OSAS were found to be more common in patients with nonspecific headaches (Table 3).

\section{Discussion}

OSAS is a common sleep disorder characterized by an obstruction in the airway resulting in continued breathing

Table 1. Epworth sleepiness scale.

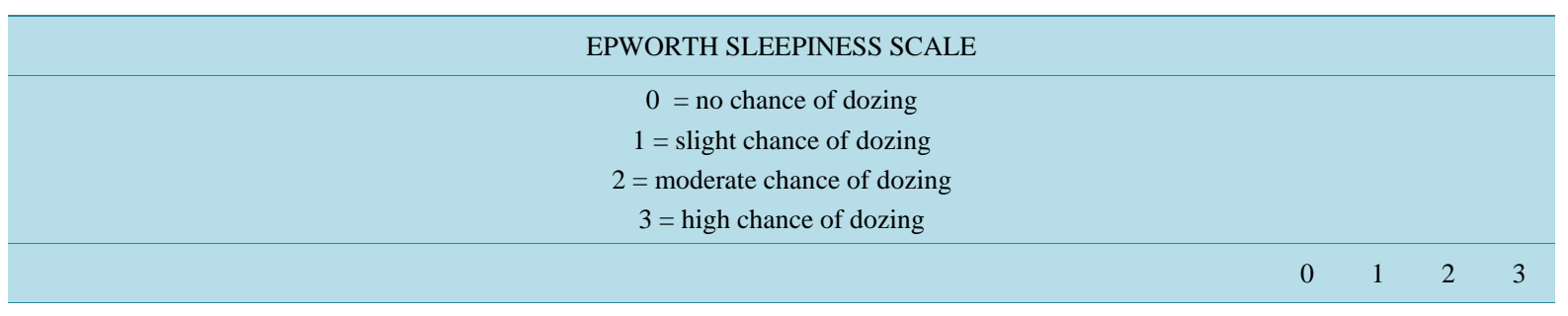

1) Sitting and reading

2) Watching TV

3) Sitting inactive in a public place (e.g. a theater or a meeting)

4) As a passenger in a car for an hour without a break

5) Lying down to rest in the afternoon when circumstances permit

6) Sitting and talking to someone

7) Sitting quietly after a lunch without alcohol

8) In a car, while stopped for a few minutes in traffic

Total Score

Table 2. Frequency of major OSAS symptoms in patients with headache.

\begin{tabular}{ccc}
\hline Major OSAS symptoms & $\mathbf{n}$ & $\mathbf{\%}$ \\
\hline Snoring & 8 & 33.3 \\
Witnessed apnea & 1 & 4.2 \\
Excessive daytime sleepiness & 5 & 20.8 \\
\hline Co-existence of major OSAS symptoms & & 62.5 \\
\hline No major symptoms & 15 & 37.5 \\
1 major symptom & 9 & 16.7 \\
2 major symptoms & 4 & 4.2 \\
\hline 3 major symptoms & 1 & 4 \\
\hline
\end{tabular}


Table 3. The frequency of major symptoms in headache patients with specific and nonspecific etiology.

\begin{tabular}{|c|c|c|}
\hline \multirow[t]{2}{*}{ Major OSAS symptoms } & $\begin{array}{c}\text { Headache with specific } \\
\text { etiology }\end{array}$ & Nonspecific headache \\
\hline & n (\%) & n (\%) \\
\hline \multicolumn{3}{|l|}{ Snoring } \\
\hline Yes $(n=8)$ & $2(25.0)$ & $6(75.0)$ \\
\hline No $(n=16)$ & $7(43.8)$ & $9(56.2)$ \\
\hline \multicolumn{3}{|l|}{ Witnessed apnea } \\
\hline Yes $(n=1)$ & $-(0)$ & $1(100)$ \\
\hline No $(n=23)$ & $9(39.1)$ & $14(60.9 .8)$ \\
\hline \multicolumn{3}{|l|}{ Excessive daytime sleepiness } \\
\hline Yes $(n=5)$ & $1(20.0)$ & $4(80.0)$ \\
\hline No $(n=19)$ & $8(42.1 .0)$ & $11(57.9)$ \\
\hline \multicolumn{3}{|c|}{ Co-existence of major symptoms } \\
\hline None & $7(46.7)$ & 8 (53.3.) \\
\hline 1 major symptom & $2(22.2)$ & $7(77.8)$ \\
\hline 2 major symptoms & $1(25.0)$ & $3(75.0)$ \\
\hline 3 major symptoms & $-(0)$ & $1(100)$ \\
\hline
\end{tabular}

effort but inadequate ventilation, leading to sleep fragmentation, excessive daytime sleepiness, mood and personality changes, cognitive insufficiency, and headaches as well [6].

Although, International Classification of Headache Disorders, second edition (ICHD-II) classifies headache attributed to OSAS as headache attributed to impaired homeostasis [8], several reports revealed that the headache prevalence in OSAS varies between 11\% - 40\% [6] [10]. The most frequent headaches reported in OSAS patients include morning headaches of tension-type, chronic daily headaches, exacerbation of migraine, or cluster headaches [6] [11] [12].

Although the exact pathogenesis of headaches in OSAS is not clear, several hypotheses have been proposed to explain the relationship between OSAS and the occurrence of headache, particularly on awakening. Night-time fluctuations of oxygen saturation during the night with hypercapnia, vasodilatation, increased intracranial pressure and impaired sleep quality are all considered as contributing factors [5] [13].

In our study, most of the patients had unidentified, nonspecific headaches. This can be associated with the low education profile of the patients, who were insufficient to describe the characteristics of their headaches. Similar to our results, some reports revealed headaches with nonspecific features in OSAS patients, too [14] [15].

Among the patients with identified headaches, we found that the most common diagnosis was exacerbation of migraine headaches (16.6\%), followed by tension-type headaches, and morning headaches, $12.5 \%$ and $4.2 \%$, respectively. Despite our low rates, particularly in morning headaches, the most common headache type was reported as tension-type morning headaches with a prevalence of $18 \%$ - 60\% in previous studies [6] [11] [12] [16].

We couldn't detect any exacerbation of cluster headaches or chronic daily headaches in our patients, but a prevalence of $53.8 \%$ was reported for cluster headaches, which were approximately 8.4 times more common in OSAS, when compared with normal individuals [17]. This rate was reported as $42.8 \%$ for chronic daily headaches in patients with OSAS, as well [18]. While our results are the preliminary outcomes, it is possible to correlate our low rates of headaches with our small number of participants.

In our study, the frequency of major OSAS symptoms was 33.3\% for snoring, $20.8 \%$ for excessive daytime sleepiness, and $4.2 \%$ for witnessed apnea. Similar to our results, habitual snoring was found to be $24 \%$ in OSAS patients with headaches, particularly chronic daily headaches [6] [19]. Despite our results, excessive daytime sleepiness frequency in children with headache was reported as $5.83 \%$ in a previous study [20]. 
In the highlight of literature review, we shared the results of our study evaluating the frequency of major OSAS symptoms, which are undeniably common sleep disorders in general population, deteriorating the quality of life. However, our study is ongoing, and these are the preliminary outcomes, even they let us consider that even patients' nonspecific headaches should be assessed about the major OSAS symptoms, as well as specific headaches such as tension-type, migraine, and etc. Thus, in case of a suspicion of sleep disorder in a headache patient it would be appropriate to question the patient about major symptoms of OSAS, and to refer to a polysomnographic evaluation for an objective diagnosis. This approach would be helpful to improve the quality of life of patients with headache.

\section{References}

[1] Merikangas, K.R., Zhang, J., Emsellem, H., Swanson, S.A., Vgontzas, A., Belouad, F., Blank, M.M., Chen, W., Einen, M., He, J.P., Heaton, L., Nakamura, E., Rooholamini, S. and Mignot, E. (2014) The Structured Diagnostic Interview for Sleep Patterns and Disorders: Rationale and Initial Evaluation. Sleep Medicine, 15, 530-535. http://dx.doi.org/10.1016/j.sleep.2013.10.011

[2] Tsara, V., Amfilochiou, A., Papagrigorakis, M.J., Georgopoulos, D. and Liolios, E. (2009) Guidelines for Diagnosis and Treatment of Sleep-Related Breathing Disorders in Adults and Children. Definition and Classification of Sleep Related Breathing Disorders in Adults: Different Types and Indications for Sleep Studies (Part 1). Hippokratia, 13, 187-191.

[3] Veldi, M., Ani, R., Vaher, H., Eller, T., Hion, T., Aluoja, A. and Vasar, V. (2010) Obstructive Sleep Apnea Syndrome (OSAS): Pathophysiology in Estonians. Pathophysiology, 17, 219-223. http://dx.doi.org/10.1016/j.pathophys.2010.01.001

[4] Kimoff, J.R., Cosio, M.G. and McGregor, M. (1991) Clinical Features and Treatment of Obstructive Sleep Apnea. Canadian Medical Association Journal, 144, 689-695.

[5] Rains, J.C. and Poceta, J.S. (2012) Sleep-Related Headaches. Neurologic Clinics, 30, 1285-1298. http://dx.doi.org/10.1016/j.ncl.2012.08.014

[6] Provini, F., Vetrugno, R., Lugaresi, E. and Montagna, P. (2006) Sleep-Related Breathing Disorders and Headache. Neurological Sciences, 27, S149-S152. http://dx.doi.org/10.1007/s10072-006-0591-1

[7] Rains, J.C., Poceta, J.S. and Penzien, D.B. (2008) Sleep and Headaches. Current Neurology and Neuroscience Reports, 8, 167-175. http://dx.doi.org/10.1007/s11910-008-0027-9

[8] Headache Classification Subcomittee of the International Headache Society (2004) The International Classification of Headache Disorders, 2nd Edition. Cephalalgia, 24, 8-160.

[9] Johns, M.W. (1999) A New Method for Measuring Daytime Sleepiness: The Epworth Sleepiness Scale. Sleep, 14, 540545.

[10] Paiva, T., Batista, A., Martins, P. and Martins, A. (1995) The Relationship between Headaches and Sleep Disturbances. Headache, 35, 590-596. http://dx.doi.org/10.1111/j.1526-4610.1995.hed3510590.x

[11] Mitsikostas, D.D., Vikelis, M. and Viskos, A. (2008) Refractory Chronic Headache Associated with Obstructive Sleep Apnoea Syndrome. Cephalalgia, 28, 139-143.

[12] Alberti, A., Mazzotta, G., Gallinella, E. and Sarchielli, P. (2005) Headache Characteristics in Obstructive Sleep Apnea Syndrome and Insomnia. Acta Neurologica Scandinavica, 111, 309-316. http://dx.doi.org/10.1111/j.1600-0404.2005.00372.x

[13] Graff-Radford, S.B. and Teruel, A. (2009) Cluster Headache and Obstructive Sleep Apnea: Are They Related Disorders? Current Pain and Headache Reports, 13, 160-163. http://dx.doi.org/10.1007/s11916-009-0027-8

[14] Neau, J.P., Paquereau, J., Bailbe, M., Meurice, J.-C., Ingrand, P. and Gil, R. (2002) Relationship between Sleep Apnoea Syndrome, Snoring and Headaches. Cephalalgia, 22, 333-339.

http://dx.doi.org/10.1046/j.1468-2982.2002.00303.x

[15] Sahota, P.K. and Dexter, J.D. (1990) Sleep and Headache Syndromes: A Clinical Review. Headache, 30, 80-84. http://dx.doi.org/10.1111/j.1526-4610.1990.hed3002080.x

[16] Idiman, F., Oztura, I., Baklan, B., Kursad, F. and Pakoz, B. (2004) Headache in Sleep Apnea Syndrome. Headache, 44, 603-606. http://dx.doi.org/10.1111/j.1526-4610.2004.446009.x

[17] Nobre, M.E., Leal, A.J. and Filho, P.M.F. (2005) Investigation into Sleep Disturbance of Patients Suffering from Cluster Headache. Cephalalgia, 25, 488-492. http://dx.doi.org/10.1111/j.1468-2982.2004.00897.x

[18] Mitsikostas, D.D., Vikelis, M. and Viskos, A. (2008) Refractory Chronic Headache Associated with Obstructive Sleep Apnoea Syndrome. Cephalalgia, 28, 139-143. 
[19] Jennum, P., Hein, H.O., Suadicani, P. and Gyntelberg, F. (1994) Headache and Cognitive Dysfunction in Snorers. A Cross-Sectional Study of 3323 Men Aged 54 - 74 Years: The Copenhagen Male Study. JAMA Neurology, 51, 937-942. http://dx.doi.org/10.1001/archneur.1994.00540210111020

[20] Luc, M.E., Gupta, A., Birnberg, J.M., Reddick, D. and Kohrman, M.H. (2006) Characterization of Symptoms of Sleep Disorders in Children with Headache. Pediatric Neurology, 34, 7-12. http://dx.doi.org/10.1016/j.pediatrneurol.2005.06.009 
Scientific Research Publishing (SCIRP) is one of the largest Open Access journal publishers. It is currently publishing more than 200 open access, online, peer-reviewed journals covering a wide range of academic disciplines. SCIRP serves the worldwide academic communities and contributes to the progress and application of science with its publication.

Other selected journals from SCIRP are listed as below. Submit your manuscript to us via either submit@scirp.org or Online Submission Portal.
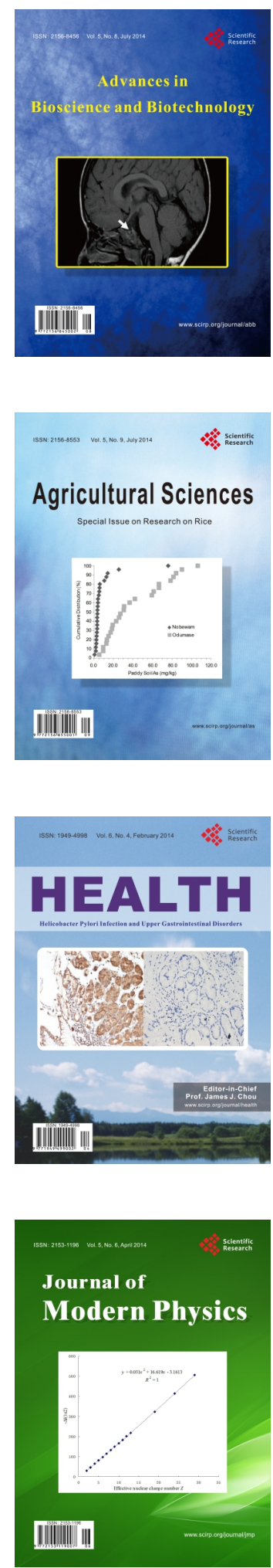
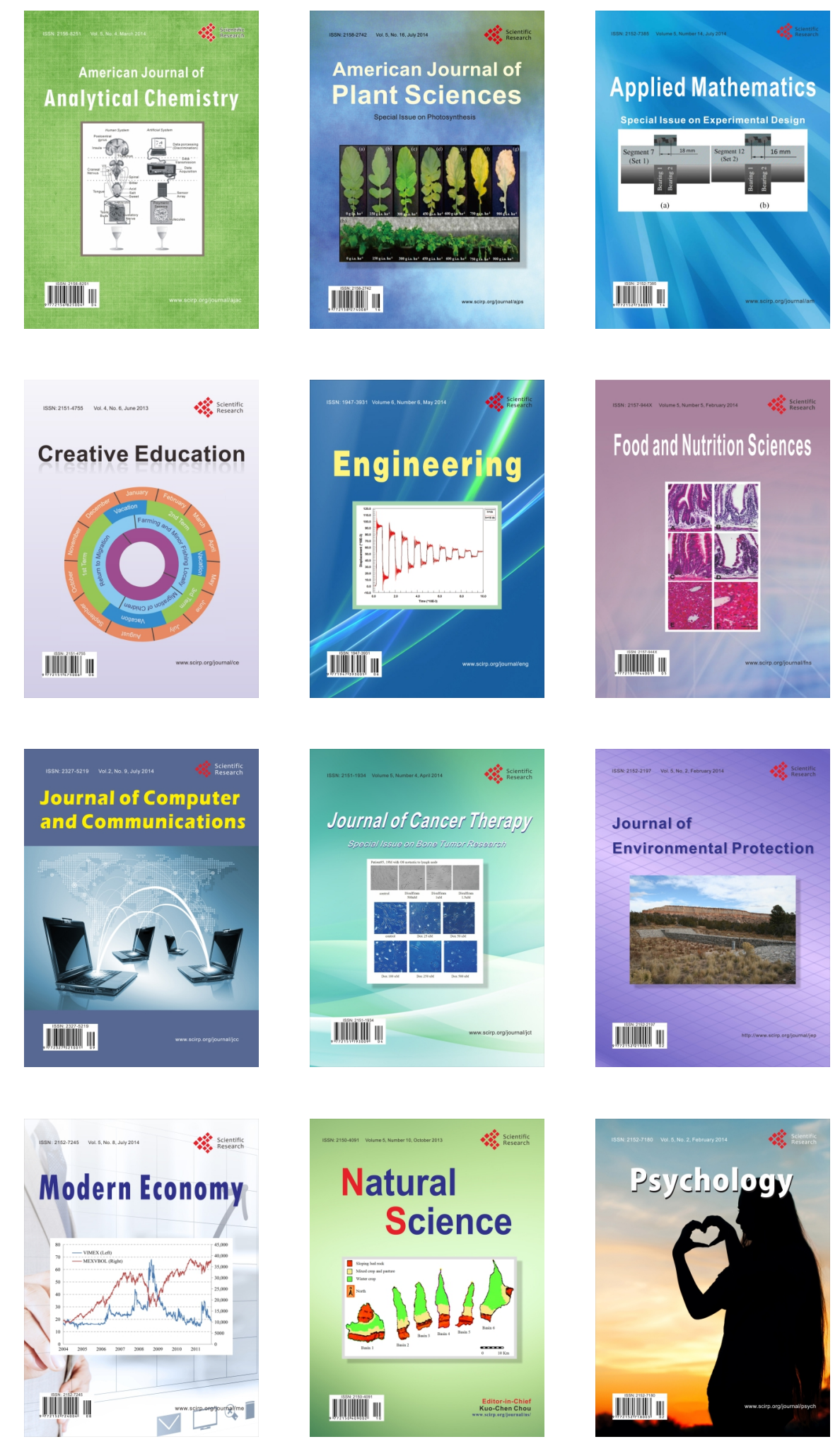